\title{
In Vitro Microscopic Evaluation of Metal- And Zirconium- Oxide-Based Crowns’ Marginal Fit
}

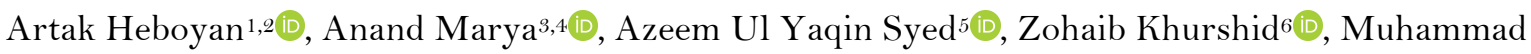 \\ Sohail Zafar ${ }^{7,8}\left(\mathbb{D}\right.$, Dinesh Rokaya ${ }^{9}$ (D), Marine Anastasyan ${ }^{10}$
}

\begin{abstract}
'Department of Prosthodontics, Faculty of Stomatology, Yerevan State Medical University after Mkhitar Heratsi, Yerevan, Armenia. ${ }^{2}$ Department of Prosthodontics, Saveetha Dental College, Saveetha Institute of Medical and Technical Sciences, Chennai, India. ${ }^{3}$ Department of Orthodontics, Faculty of Dentistry, University of Puthisastra, Phnom Penh, Cambodia.

${ }^{4}$ Center for Transdisciplinary Research, Saveetha Dental College, Saveetha Institute of Medical and Technical Science, Saveetha University, Chennai, India.

${ }^{5}$ Department of Prosthodontics, University of Science and Technology of Fujairah, Fujairah, United Arab Emirates.

${ }^{6}$ Department of Prosthodontics and Implantology, College of Dentistry, King Faisal University, Al-Hofuf, Saudi Arabia.

${ }^{7}$ Department of Restorative Dentistry, College of Dentistry, Taibah University, Al Madinah, Saudi Arabia.

${ }^{8}$ Department of Dental Materials, Islamic International Dental College, Riphah International University, Islamabad, Pakistan.

${ }^{9}$ Department of Clinical Dentistry, Walailak University International College of Dentistry, Walailak University, Bangkok, Thailand.

${ }^{10}$ Art Classic Dent Dental Centre, Yerevan, Armenia.
\end{abstract}

Correspondence: Anand Marya, Department of Orthodontics, Faculty of Dentistry, University of Puthisastra, Phnom Penh, Cambodia. E-mail: amarya@puthisastra.edu.kh

Academic Editor: Alessandro Leite Cavalcanti

Received: 27 July 2021 / Review: 14 August 2021 / Accepted: 29 September 2021

How to cite: Heboyan A, Marya A, Syed AUY, Khurshid Z, Zafar MS, Rokaya D, et al. In vitro microscopic evaluation of metal- and zirconium-oxide-based crowns' marginal fit. Pesqui Bras Odontopediatria Clín Integr. 2022; 22:e2 10144. https://doi.org/10.1590/pboci.2022.010

\begin{abstract}
Objective: To evaluate the marginal adaptation of computer-aided designing and computer-aided machining (CAD/CAM) fabricated cobalt-chromium and zirconium-oxide-based ceramic crowns compared to those produced by a conventional method. Material and Methods: The study consists of three groups; 45 crowns fabricated from cobalt-chromium (CAD-CoCr) and 45 crowns manufactured from zirconium CAD/CAM technology (CAD-Z), and 45 control (C) which consists of conventional metal-ceramic crowns. The marginal discrepancies in vertical dimensions were assessed utilizing a microscope in four surfaces (mesial, distal, vestibular, and oral) for each crown. On completion of the microscopic evaluation, multivariate analysis of variance (MANOVA) was used to study the difference in the four surfaces, considered altogether. Two-way ANOVA revealed the effect of three systems used for gap measurements of each landmark. The differences observed were considered significant at $\mathrm{p}<0.05$. Results: There were no differences in the four surfaces revealed by ANOVA in the three groups when considered altogether. Twoway ANOVA of each surface discovered no differences among all groups as well. Conclusion: The CAD/CAM crowns revealed a comparable and satisfactory marginal adaptation compared to conventional metal-ceramic crowns.
\end{abstract}

Keywords: Dental Prosthesis; Crowns; Zirconium; Gingiva; Dental Porcelain. 


\section{Introduction}

Presently, the use of ceramic restorations has considerably increased in dentistry [1] due to their constant improvement in such characteristics as aesthetics, biocompatibility, greater resistance to staining, corrosion, wear, and mastication forces time [2,3]. Clinical success and longevity of restorations are determined by the mechanical, biological, and esthetic requirements. Further, a good impression also helps in the success of the prosthetic restoration [4]. Silicone elastomeric polymers are widely used in dentistry, and among them, polyvinyl siloxane is considered the first line of impression material for making prosthetic crowns and veneers due to its high accuracy and dimensional stability [5,6]. Good impressions are also crucial for the internal and marginal adaptations, structural rigidity, and maintenance of pulpal and periodontal health as they are essential for the longevity of the restorations [7]. Several factors such as the condition of abutment teeth, construction type, pontic design, occlusion, restorative biomaterial used may contribute to the durability of fixed prosthetic constructions, with the internal and marginal fit of restoration being the most essential $[8,9]$.

Meanwhile, design preparation, the form of the finish line, restoration material and technique, cement type, dentist's expertise, among other factors, might impact the restoration adaptation [10-12]. Marginal distortion around metal-ceramic construction might occur at any stage of fabrication. The increased marginal discrepancy results in the thicker layer of cement affected by the oral cavity environment, causing cement dissolution, with further tooth biofilm accumulation, marginal discoloration, and hypersensitivity. Other expected consequences include caries, gingival crevicular fluid overflow, microleakage, pulpal infection, subsequent bone loss, and the development of periodontal pathology [10-13]. In addition, the insufficient internal fit might bring restoration retention deficiency and low resistance to the tooth-restoration complex $[10]$.

Various fabrication techniques for various types of constructions are described in the literature. The wide application of computer-aided designing and computer-aided machining (CAD/CAM) systems among dentists is conditioned by the simplification of their clinical and laboratory procedures [14,15]. Clinical evaluation of marginal adaptation is carried out by probing. Marginal adaptation is evaluated using radiographic examination and scanning electron microscopy [16-19]. The silicone replica is another nondestructive technique to assess the internal and marginal adaptation. The gap between the prepared tooth and the internal surface of the construction is recorded by a light body polyvinylsiloxane impression material [17]. However, there is still no standard of the acceptable value of marginal fit. The acceptable value ranges from lower or equal to $120 \mu \mathrm{m}[15,16]$ to that less than $100 \mu \mathrm{m}$ [20-23]. Another study revealed no significant difference between marginal fit between the crowns fabricated from lost wax and CAD/CAM lithium disilicate [19]. There is existing data on a more considerable marginal discrepancy in the crown fabricated by the CAD/CAM technology [20,21]. One study suggested the mean marginal discrepancy values of $86.64 \mu \mathrm{m}$ for CAD/CAM machining, $96.23 \mu \mathrm{m}$ for direct metal laser sintering, and $75.92 \mu \mathrm{m}$ for conventional casting [24]. Studies also show that the marginal adaptation of conventional and CAD/CAM-fabricated lithium disilicate crowns was inconsistent [25-30].

The latest systematic review reported insufficient data on crown restorations' internal and marginal fit [25-27]. Hence, the study's objective was to assess in vitro the marginal adaptation of single CAD/CAMfabricated cobalt-chromium and zirconium-oxide-based ceramic crowns compared to those fabricated by the conventional method. 


\section{Material and Methods}

Study Samples

The overview of the study is shown in Figure 1. A total of 135 unprepared, intact phantom teeth attached to the phantom jaws were selected. All procedures were carried out by one operator with the same technique applied.

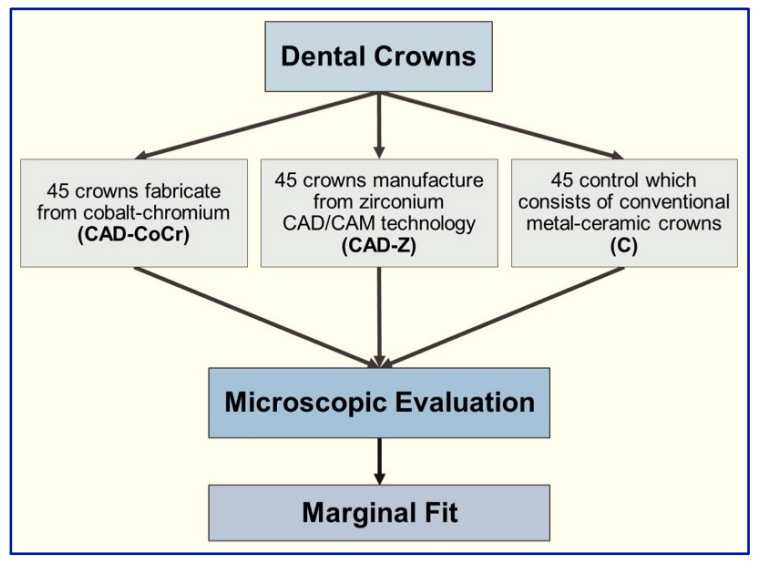

Figure 1. Overview of the study.

Tooth Preparation Protocol

The teeth were prepared following standards, i.e., with 1.5-2.0 mm incisal/occlusal reduction; 1-1.5 $\mathrm{mm}$ axial reduction, and $360^{\circ}$ rounded shoulder located in the cervical area. According to the proper guideline [31], the tooth preparations for the conventional metal-ceramic and CAD/CAM fabricated restorations were made similar [32].

The preparation of the selected teeth started from making 3 depth grooves (tooth midline, mesiofacial and distofacial) on the tooth vestibular surface. Depth grooves were also placed in the incisal/occlusal region to ensure adequate and even tooth reduction. Groove depth was verified using a silicone index and periodontal probe. After reducing the appropriate amount of tooth structure from the incisal/occlusal region, a preparation of the vestibular surface in cervical and incisal planes was carried out. Tooth structure was removed between the depth grooves, making a round shoulder margin at the cervical region. The width of the round shoulder margin was $1 \mathrm{~mm}$, which was confirmed by a periodontal probe. When vestibular surface preparation was completed, axial reduction of lingual and proximal surfaces was carried out, keeping rotary diamond instrument parallel to the path of insertion of the crown. A football-shaped diamond bur was used to prepare the lingual surface of anterior teeth. During the finishing procedure, the line angles were rounded to facilitate the impression-making and die-pouring steps. A flat-ended diamond in a low-speed handpiece was used to create the flat shoulder margin.

\section{Fabrication of Various Crowns}

Impression making procedure was carried out using standard metallic impression trays (Zhermack SpA, Badia Polesine, RO, Italy), which have high deformation resistance as well as provide greater precision of the impression. Polyvinyl siloxane polymer impression material (Zhermack SpA, Badia Polesine, RO, Italy) was used to take impressions from the prepared teeth, and a two-layer one-step impression technique is applied. After setting, the polyvinyl siloxane polymer impression material was removed from the artificial jaw 
and poured with type $\mathrm{V}$ dental stone (Heraeus Kulzer, Hanau, Germany) according to the manufacturer's instructions. All prepared 135 teeth were divided into three groups (Figure 2). The study consists of three groups; 45 crowns fabricated from cobalt-chromium (CAD-CoCr) and forty-five crowns fabricated from zirconium (CAD-Z) CAD/CAM technology, and 45 control crowns (C) consisting of conventional metalceramic crowns.

Group CAD-CoCr: Optical 3D scanning (Lava Scan; 3M ESPE, Seefeld, Germany) was used for digitizing the casts. The preset cement space was designed $50 \mu \mathrm{m}$ for all copings since this provides the least marginal discrepancy [33,34]. The milling was carried out from the pre-sintered hard Co-Cr blocks (CORITEC Co-Cr disc; imes-icore GmbH, Eiterfeld, Germany) to fabricate 45 metal copings with the CAD/Milling system. After milling the crowns, the cleaning was done meticulously with a steam cleaner, blow-dried in an airstream, and examined the fit. Finally, porcelain was applied to the comings in layers and sintered according to acceptable protocols in a special furnace (Programat P310; Ivoclar Vivadent AG, Schaan, Liechtenstein) [35,36].

Group CAD-Z: The casts of this group were digitized using the same scanner (Lava Scan; 3M ESPE) and the same method as for CAD-CoCr. Milling was carried out from the semi-sintered zirconia by a three-axis milling machine (Lava Form; 3M ESPE, Seefeld, Germany). Sintering of copings was carried out in a special furnace (Lava Therm; 3M ESPE, Seefeld, Germany) for eight hours and was veneered by appropriate ceramics (Lava Ceram; 3M ESPE, Seefeld, Germany). The final restorations were tested, fitted on their corresponding casts, and glazed.

Group C: The 45-regular metal-ceramic crowns were fabricated with metal copings made from cobaltchromium alloy and layered feldspathic ceramic (Vita Vm9; Vita Zahnfabrik, Bad Sackingen, Germany). Sintering of all the crowns was done in a ceramic furnace (Programat P310; Ivoclar Vivadent AG, Schaan, Liechtenstein).

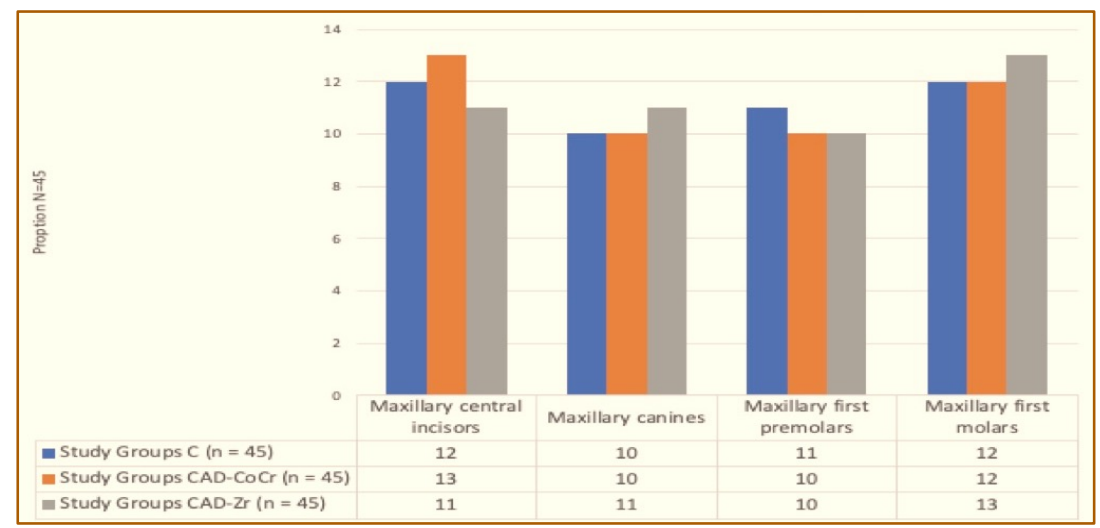

Figure 2. Distribution of the studied 135 teeth in three groups.

The definitive crowns were evaluated visually and utilized zoning afterward. A viscous layer of silicone impression material was used (Elite HD+ Super Light Body, Fast Set) to assess the restoration adaptation, and all necessary correction was made, if needed.

\section{Marginal Gap Measurement}

The analysis of marginal fit between the crown and preparation margins was carried out under a 3D optical microscope with an accuracy of $1 \mu \mathrm{m}$ and a magnification of 250x (Roi, RAM Optical Instrumentation, 
Irvine, CA, USA). The measurement was defined as the vertical marginal discrepancy by Holmes et al. [37]. One operator carried out all measurements. The values below $1 \mu \mathrm{m}$ were considered 0.

Statistical Analysis

Descriptive statistics from every crown's four surfaces (mesial, distal, vestibular, and oral) were applied. Multivariate analysis of variance (MANOVA) was done to define whether the four surfaces altogether varied between groups. Two-way ANOVA was carried out to define a comprehensive assessment for each surface and to conclude how three techniques used to fabricate the crowns influenced the gap measurements. Significance was set at $\mathrm{p}<0.05$.

\section{Results}

Figure 3 shows the descriptive statistics of the four surfaces of the crowns (mesial, distal, vestibular, and oral) for each group (C, CAD-CoCr, CAD-Z). MANOVA disclosed no significant differences between the four surfaces when considered altogether in the three observation groups $(p<0.001)$. Two-way ANOVA disclosed no quantitative differences in the three study groups $(\mathrm{p}<0.0001$ for each surface).

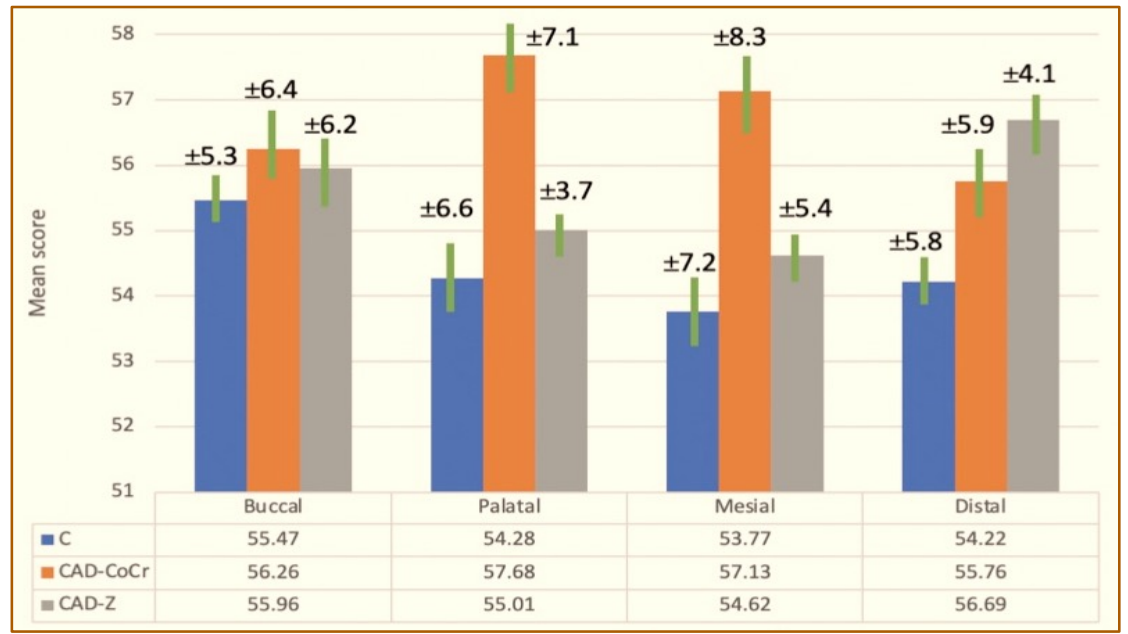

Figure 3. Mean and standard deviation $(\mu \mathrm{m})$ of the four surfaces (vestibular, oral, mesial, and distal) at all crowns for all groups.

\section{Discussion}

The current study investigated the marginal adaptation of conventional metal-ceramic, CAD/CAMfabricated cobalt-chromium, and zirconium-oxide-based ceramic made using the polyvinyl siloxane polymer impression material as they are widely used in making impressions due to high accuracy $[5,6]$. This study revealed that crown type did not considerably influence marginal fit. Thus, the null hypothesis was partially rejected. In conventional restorations, the finish line impacts marginal fit either, providing a cement outflow of a certain amount. Finishing with a beveled shoulder ensures smaller marginal discrepancy, while deep chamfer provides better internal adaptation [29]. Generally, deep chamfer and round shoulder are considered two main finish lines for metal-free crowns. However, the round shoulder finish line provides better marginal adaptation values than the deep chamfer, while the application of ceramics affects the marginal adaptation. The variations in the marginal adaptation, which take place at various stages of manufacturing, were also assessed by some researchers [30]. 
Another study revealed no difference between the digital and conventional's marginal fit crowns [18,38]. Nevertheless, these findings differ from the study results reported about the advantage of the conventional method for single metal crown fit [9,32] and the benefit of the digital method for metal crowns [24,27]. The variance in these study results could be due to the wide range of measurement protocols, specimen design, sample size, and tooth type. Metal and zirconia frameworks manufactured by direct scanning, impression scanning, and lost-wax techniques were reported to show similar marginal discrepancies [26]. Recently published clinical studies showed that CAD/CAM fabricated metal and zirconia-based restorations demonstrated better clinical outcomes due to improved marginal fit over conventionally fabricated metal-based restorations [35,39-41]. Previously published results were found not to coincide with the data obtained in the present study. First, it can be due to differences in study designs (in vivo versus in vitro). Furthermore, we aimed to assess only crowns marginal fit. However, the mentioned studies included both crowns and fixed partial dentures, which also can affect the final results.

The means for the studied groups ranged within the acceptable limits reported in the literature $[17,18]$. However, the sufficient value of marginal fit has not been standardized yet. Different specialists suggest a range of fair values from lower or equal to $120 \mu \mathrm{m}$ [19]. Particular difficulties in comparing the results of various researches arose due to a great diversity of restorative materials and CAD/CAM techniques, the difference in the terms used to define marginal fit, and various methods for quantifying marginal fit [9].

No general opinion on a definite number of measurements required is found in the literature. Gassino et al. [42] used 18 and 90 measurement sites for study and clinical crowns, respectively, to produce a sample mean value $\pm 5 \mu \mathrm{m}$ of the true mean. Nawafleh et al. [43] suggested testing at least 30 specimens with 50 measurements each to provide reliable data.

This is an in-vitro study and has the advantage over clinical research. The impression materials are the vulnerability to the dentine as they can remain inside the dentinal tubules while making an impression that can adversely affect the crown adhesion and subsequent adhesion marginal adaptation [38,44,45]. Dentinal tubules contaminations from oral fluids have also been found during tooth preparation and impression procedures [46-50]. Moreover, cement selection is also vital in marginal adaptation of fixed restorations [51,52]. The replica technique has been widely used in in-vitro and in-vivo studies both and the results obtained are reliable and accurate. The only major drawback that has been seen in using this technique is that there have been reports of the elastomeric film tearing when removed. There have also been reports of problems in identifying the finish lines as well as the margins of the crowns [53].

The limitations of this study are that the measurements obtained in the process of in vitro study might differ from those acquired during in vivo studies. The accuracy of the crown fit is estimated by the measurements of both horizontal and vertical planes. Only vertical gaps were assessed in this study. Also, any internal discrepancies that could impact the crown's strength were not considered in this study. The study confirmed that proper marginal fit in single-unit crowns could be achieved using CAD/CAM systems. However, further research should be done to create various finish lines of preparation and evaluate marginal fit under different cement types. Moreover, the accuracy of the crown adaptation should be assessed both in horizontal and vertical planes.

\section{Conclusion}

The type of crown (conventional metal-ceramic, CAD/CAM-fabricated cobalt-chromium-based ceramic, and zirconium-oxide-based ceramic) did not have a significant effect on the marginal fit. The 
CAD/CAM fabricated restorations demonstrate a comparable and satisfactory marginal adaptation in singleunit crowns compared to conventional ones. In addition, the manufacturing technique of different single crowns did not affect the marginal gaps.

\section{Authors' Contributions}

\begin{tabular}{|c|c|c|}
\hline $\mathrm{AH}$ & (D) https://orcid.org/0000-0001-8329-3205 & $\begin{array}{l}\text { Conceptualization, Methodology, Formal Analysis, Investigation, Data Curation, Writing - } \\
\text { Review and Editing and Project Administration. }\end{array}$ \\
\hline AM & (iD) https://orcid.org/0000-0003-2009-4393 & Validation, Data Curation, Writing - Review and Editing and Visualization. \\
\hline AUYS & (iD) https://orcid.org/0000-0002-0116-7449 & Data Curation, Writing - Review and Editing and Visualization. \\
\hline ZK & (D) https://orcid.org/0000-0001-7998-7335 & Writing - Review and Editing and Visualization. \\
\hline MSZ & (iD) https://orcid.org/0000-0002-5157-7067 & Writing - Review and Editing and Visualization. \\
\hline DR & (iD) https://orcid.org/0000-0002-3854-667X & Writing - Review and Editing and Visualization. \\
\hline MA & -- & Methodology, Software, Investigation, Data Curation and Writing - Review and Editing. \\
\hline
\end{tabular}

\section{Financial Support}

None.

\section{Conflict of Interest}

The authors declare no conflicts of interest.

\section{Data Availability}

The data used to support the findings of this study can be made available upon request to the corresponding author.

\section{References}

[1] Jurado CA, Villalobos-Tinoco J, Tsujimoto A, Castro P, Torrealba Y. The art of minimal tooth reduction for veneer restorations. European J Gen Dent 2020; 9(1): 45-52. https://doi.org/10.4103/ejgd.ejgd_173_19

[2] Forrer FA, Schnider N, Brägger U, Yilmaz B, Hicklin SP. Clinical performance and patient satisfaction obtained with tooth-supported ceramic crowns and fixed partial dentures. J Prosthet Dent 2020; So022-3913(19):30542-46. https://doi.org/10.1016/j.prosdent.2019.08.012

[3] Demir N, Ozturk AN, Malkoc MA. Evaluation of the marginal fit of full ceramic crowns by the micro computed tomography (micro CT) technique. Eur J Dent 2014; 8(4): 437-444. https://doi.org/10.4103/1305-7456.143612

[4] Martins F, Reis J, Barbero Navarro I, Maurício P. Dimensional stability of a preliminary vinyl polysiloxane impression material. Dent J 2019; 7(3):81. https://doi.org/10.3390/dj7030081

[5] Xu Y, Unkovskiy A, Klaue F, Rupp F, Geis-Gerstorfer J, Spintzyk S. Compatibility of a silicone impression/adhesive system to FDM-printed tray materials - a laboratory peel-off study. Materials 2018; 11(10):1905. https://doi.org/10.3390/ma11101905

[6] Rokaya D, Mahat Y, Sapkota B, Kc Basnyat S. Full coverage crowns and resin-bonded bridge combination for missing mandibular anterior teeth. Kathmandu Univ Med J 2018; 16(61):97-9.

[7] Pelekanos S, Koumanou M, Koutayas SO, Zinelis S, Eliades G. Micro-CT evaluation of the marginal fit of different In-Ceram alumina copings. Eur J Esthet Dent 2009; 4(3): 278-92.

[8] Kokubo Y, Ohkubo C, Tsumita M, Miyashita A, Vult von Steyern P, Fukushima S. Clinical marginal and internal gaps of Procera All Ceram crowns. J Oral Rehabil 2005; 32(7):526-30. https://doi.org/10.1111/j.1365-2842.2005.01458.x

[9] Boitelle P, Tapie L, Mawussi B, Fromentin O. Evaluation of the marginal fit of CAD-CAM zirconia copings: comparison of 2D and 3D measurement methods. J Prosthet Dent 2018; 119(1):75-81. https://doi.org/10.1016/j.prosdent.2017.01.026

[10] Conrad HJ, Seong WJ, Pesun IJ. Current ceramic materials and systems with clinical recommendations: a systematic review. J Prosthet Dent 2007; 98(5):389-404. https://doi.org/10.1016/So022-3913(07)60124-3

[11] Bottino MA, Valandro LF, Buso L, Ozcan M. The influence of cervical finish line, internal relief, and cement type on the cervical adaptation of metal crowns. Quintessence Int. 2007; 38(7): e425-e432.

[12] An S, Kim S, Choi H, Lee JH, Moon HS. Evaluating the marginal fit of zirconia copings with digital impressions with an intraoral digital scanner. J Prosthet Dent 2014; 112(5):1171-5. https://doi.org/10.1016/j.prosdent.2013.12.024

[13] Faot F, Suzuki D, Senna PM, da Silva WJ, de Mattias Sartori IA. Discrepancies in marginal and internal fits for different metal and alumina infrastructures cemented on implant abutments. Eur J Oral Sci 2015; 123(3):215-9. https://doi.org/10.1111/eos.12181 
[14] Beuer F, Schweiger J, Edelhoff D. Digital dentistry: an overview of recent developments for CAD/CAM generated restorations. Br Dent J 2008; 204(9):505-11. https://doi.org/10.1038/sj.bdj.2008.350

[15] Alghazzawi TF, Al-Samadani KH, Lemons J, Liu PR, Essig ME, Bartolucci AA, et al. effect of imaging powder and CAD/CAM stone types on the marginal gap of zirconia crowns. J Am Dent Assoc 2015; 146(2):111-20. https://doi.org/10.1016/j.adaj.2014.10.006

[16] Contrepois M, Soenen A, Bartala M, Laviole O. Marginal adaptation of ceramic crowns: a systematic review. J Prosthet Dent 2013; 110(6):447-454.e10. https://doi.org/10.1016/j.prosdent.2013.08.003

[17] Rahme HY, Tehini GE, Adib SM, Ardo AS, Rifai KT. In vitro evaluation of the "replica technique" in the measurement of the fit of Procera crowns. J Contemp Dent Pract 2008; 9(2):25-32.

[18] Shembesh M, Ali A, Finkelman M. An in vitro comparison of the marginal adaptation accuracy of CAD/CAM restorations using different impression systems. J Prosthodont 2017; 26(7):581-6. https://doi.org/10.1111/jopr.12446

[19] Tan PL, Gratton DG, Diaz-Arnold AM, Holmes DC. An in vitro comparison of vertical marginal gaps of CAD/CAM titanium and conventional cast restorations. J Prosthodont 2008; 17(5):378-83. https://doi.org/10.1111/j.1532-849X.2008.00302.x

[20] Reich S, Gozdowski S, Trentzsch L, Frankenberger R, Lohbauer U. Marginal fit of heat-pressed vs. CAD/CAM processed all-ceramic onlays using a milling unit prototype. Oper Dent 2008; 33:644-50. https://doi.org/10.2341/07-162

[21] Ushiwata O, Moraes JV. Method for marginal measurements of restorations: Accessory device for toolmakers microscope. J Prosthet Dent 2000; 83:362-6. https://doi.org/10.1016/So022-3913(00)70141-7

[22] Neves FD, Prado CJ, Prudente MS, Carneiro TA, Zancopé K, Davi LR, et al. Micro-computed tomography evaluation of marginal fit of lithium disilicate crowns fabricated by using chairside CAD/CAM systems or the heat-pressing technique. J Prosthet Dent 2014; 112(5):1 134-40. https://doi.org/10.1016/j.prosdent.2014.04.028

[23] Mously HA, Finkelman M, Zandparsa R, Hirayama H. Marginal and internal adaptation of ceramic crown restorations fabricated with CAD/CAM technology and the heat-press technique. J Prosthet Dent 2014; 112(2):24956. https://doi.org/10.1016/j.prosdent.2014.03.017

[24] Freire Y, Gonzalo E, Lopez-Suarez C, Suarez MJ. The marginal fit of CAD/CAM monolithic ceramic and metalceramic crowns. J Prosthodont 2017; 28(3):1-6. https://doi.org/10.1111/jopr.12590

[25] Tamac E, Toksavul S, Toman M. Clinical marginal and internal adaptation of CAD/CAM milling, laser sintering, and cast metal ceramic crowns. J Prosthet Dent 2014; 12(4):909-13. https://doi.org/10.1016/j.prosdent.2013.12.020

[26] Lee B, Oh KC, Haam D, Lee JH, Moon HS. Evaluation of the fit of zirconia copings fabricated by direct and indirect digital scanning procedures. J Prosthet Dent 2018; 120(2):225-31. https://doi.org/10.1016/j.prosdent.2017.08.003

[27] Kocaağaoğlu H, Kılınç HI, Albayrak H. Effect of digital impressions and production protocols on the adaptation of zirconia copings. J Prosthet Dent 2017; 117(1):102-8. https://doi.org/10.1016/j.prosdent.2016.06.004

[28] Nagarkar SR, Perdigão J, Seong WJ, Theis-Mahon N. Digital versus conventional impressions for full-coverage restorations: a systematic review and meta-analysis. J Am Dent Assoc 2018; 149(2):139-47. https://doi.org/10.1016/j.adaj.2017.10.001

[29] Souza RO, Ozcan M, Pavanelli CA, Buso L, Lombardo GH, Michida SM, Mesquita AM, et al. Marginal and internal discrepancies related to margin design of ceramic crowns fabricated by a CAD/CAM system. J Prosthodont 2012; 21(2):94-100. https://doi.org/10.1111/j.1532-849X.2011.00793.x

[30] Miura S, Inagaki R, Kasahara S, Yoda M. Fit of zirconia all-ceramic crowns with different cervical margin designs, before and after porcelain firing and glazing. Dent Mater J 2014; 33(4):484-89. https://doi.org/10.4012/dmj.2013-284

[31] Rosenstiel SF, Land MF, Fujimoto J. Contemporary Fixed Prosthodontics. $5^{\text {th }}$. ed. St. Louis: Mosby/Elsevier Inc.; 2016.

[32] Biscaro L, Bonfiglioli R, Soattin M, Vigolo P. An in vivo evaluation of fit of zirconium-oxide based ceramic single crowns, generated with two CAD/CAM systems, in comparison to metal ceramic single crowns. J Prosthodont 2013; 22(1):36-41. https://doi.org/10.1111/j.1532-849X.2012.00907.x

[33] Mosharraf R, Azizi A, Naziri B, Abolhasani M. The effects of cement space thickness and material type on marginal discrepancy of restoration. Braz Dent Sci 202 1; 24(1):1-8. https://doi.org/10.14295/bds.2021.v24i1.1968

[34] Elbadawy AA, Elaziz MHA, Alnazzawi AA, Borzangy SS. Effect of various digital cement space settings on the adaptation of CAD/CAM occlusal veneer "micro-ct evaluation". Dent Mater J 2021; 40(3):625-30. https://doi.org/10.4012/dmj.2020-226

[35] Heboyan A, Manrikyan M, Zafar MS, Rokaya D, Nushikyan R, Vardanyan I, et al. Bacteriological evaluation of gingival crevicular fluid in teeth restored using fixed dental prostheses: an in vivo study. Int J Mol Sci 2021; 22(11):5463. https://doi.org/10.3390/ijms22115463

[36] Mohamed MS, Mohsen CA, Katamish H. Impact of chemical aging on the fracture resistance of two ceramic materials: zirconia-reinforced lithium silicate and lithium disilicate ceramics. Open Access Maced J Med Sci 2020; 8(D):189-93. https://doi.org/10.3889/oamjms.2020.5155 
[37] Holmes JR, Bayne SC, Holland GA, Sulik WD. Considerations in measurement of marginal fit. J Prosthet Dent 1989; 62(4):405-8. https://doi.org/10.1016/0022-3913(89)90170-4

[38] Sakornwimon N, Leevailoj C. Clinical marginal fit of zirconia crowns and patients' preferences for impression techniques using intraoral digital scanner versus polyvinyl siloxane material. J Prosthet Dent 2017; 118(3):386-91. https://doi.org/10.1016/j.prosdent.2016.10.019

[39] Heboyan A, Syed AUY, Rokaya D, Cooper PR, Manrikyan M, Markaryan M. Cytomorphometric analysis of inflammation dynamics in the periodontium following the use of fixed dental prostheses. Molecules 2020; 25(20):4650. https://doi.org/10.3390/molecules25204650

[40] Heboyan AG, Manrikyan ME, Markaryan MM, Vardanyan IF. Changes in the parameters of gingival crevicular fluid in masticatory function restoration by various prosthodontic constructions. Int J Pharm Sci Res 2020; 12(2):2088-93. https://doi.org/10.31838/ijpr/2020.12.02.280

[41] Avetisyan A, Markaryan M, Rokaya D, Tovani-Palone MR, Zafar MS, Khurshid Z, et al. Characteristics of periodontal tissues in prosthetic treatment with fixed dental prostheses. Molecules 2021; 26(5):1331. https://doi.org/10.3390/molecules26051331

[42] Gassino G, Monfrin SB, Scanu M, Spina G, Preti G. Marginal adaptation of fixed prosthodontics: a new in vitro 360degree external examination procedure. Int J Prosthodont 2004; 17(2):218-23.

[43] Nawafleh NA, Mack F, Evans J, Mackay J, Hatamleh MM. Accuracy and reliability of methods to measure marginal adaptation of crowns and FDPs: a literature review. J Prosthodont 2013; 22(5):419-28. https://doi.org/10.1111/jopr.12006

[44] Park JK, Lee WS, Kim HY, Kim WC, Kim JH. Accuracy evaluation of metal copings fabricated by computer-aided milling and direct metal laser sintering systems. J Adv Prosthodont 2015; 7(2):122-8. https://doi.org/10.4047/jap.2015.7.2.122

[45] Heboyan AG, Muradyan RG. Impression material selection and soft tissue management in contemporary fixed prosthodontics. Web of Scholar 2019; 5(35):9-15. https://doi.org/10.31435/rsglobal_wos/31052019/6499

[46] Richardson D, Tao L, Pashley DH. Dentin permeability: Effects of crown preparation. Int J Prosthodont 1991; $4(3): 219-25$.

[47] Sinjari B, D'Addazio G, Xhajanka E, Caputi S, Varvara G, Traini T. Penetration of different impression materials into exposed dentinal tubules during the impression procedure. Materials 2020; 13(6):1321. https://doi.org/10.3390/ma13061321

[48] Juneja R, Duhan J, Tewari S, Sangwan P, Bhatnagar N. Effect of blood contamination and decontamination protocols on acetone-based and ethanol-based total etch adhesive systems. J Esthet Restor Dent 2014; 26(6):403-16. https://doi.org/10.1111/jerd.12089

[49] Kilic K, Arslan S, Demetoglu GA, Zararsiz G, Kesim B. Do blood contamination and haemostatic agents affect microtensile bond strength of dual cured resin cement to dentin? J Appl Oral Sci 2013; 21(1):85-91. https://doi.org/10.1590/1678-7757201302147

[50] Heboyan AG. Marginal and internal fit of fixed prosthodontic constructions: a literature review. Int J Dent Res Rev 2019; 2(19):1-8. https://doi.org/10.28933/ijdrr-2019-06-1105

[51] Heboyan AG, Vardanyan AR, Avetisyan AA. Cement selection in dental practice. World Sci $2019 ; 3(43): 2$. https://doi.org/10.31435/rsglobal_ws/31032019/6405

[52] Durairaj RB, Sivasaravanan S, Sharma DK, Ramachandran S, Heboyan A. Investigations on mechanical properties of titanium reinforced glass ionomer cement $(\mathrm{GiC})$ - ceramic composites suitable for dental implant applications. Dig J Nanomater Biostructures 2021; 16(1):161-7.

[53] Tamim H, Skjerven H, Ekfeldt A, Rønold HJ. Clinical evaluation of CAD/CAM metal-ceramic posterior crowns fabricated from intraoral digital impressions. Int J Prosthodont 2014; 27(4):331-7. https://doi.org/10.1 1607/ijp.3607 